\title{
Research on Innovation of Market Adaptability of Small and Micro Enterprises
}

\author{
Xiansheng Liu \\ Xi'an International University, Xi'an, Shaanxi, 710077
}

\begin{abstract}
This article discusses the concept and characteristics of small and micro enterprises, and based on the statistical data on Chinese small and micro enterprises in-depth analysis of the status quo to identify the current development of small and micro enterprises in Chinese existing problems. Small and micro enterprises with its flexible market adaptability have become an important force in Chinese economic construction. Based on the analysis of the factors affecting the market adaptability of small and micro enterprises, a multi-level extension comprehensive evaluation method is applied to a small micro enterprise And put forward measures to improve the market adaptability of small and micro enterprises.

Keywords: Market Adaptability, Small and Micro Enterprises, Innovation Research
\end{abstract}

\section{Introduction}

Small and micro enterprises have obviously become an important part of Chinese national economic development, also played an extremely important supporting role in social development, especially in the promotion of national economic growth, industrial restructuring, employment, improve people's living standards , Technological innovation and other aspects of products play an increasingly important role. However, although small and micro enterprises have made more and more contributions to Chinese economic development, for small and micro enterprises, their own survival and development is difficult. Although China has introduced a lot of support policies to encourage the development of small and 
micro enterprises, but according to the SME Association on Chinese SME Development Report data analysis, the fourth quarter of 2012 China SME Development Index (SMEDI) rebounded to 90.8 than the third quarter Up 3.3 points. In the first quarter of 2013, the China SME index continued to rise to 95.2, up 4.4 points from the fourth quarter of 2012, and rebounded sharply in two consecutive quarters. However, experts pointed out that Chinese SME development index, although the momentum of continuous recovery, but the need to consolidate. The difficulties in the cost, market and financing of the production and operation of large and medium-sized enterprises have not changed significantly, and the rise of the corresponding sub-indexes has great pressure.

In the reform and opening up more than 30 years, Chinese economic development has achieved remarkable results, the total economy has been living in the world's second, becoming an influential global emerging economies and industrial manufacturing power. But in the development process, we have paid a lot of costs, long-term accumulation of the irrational economic structure of the contradictions, the development of uncoordinated, unbalanced and unsustainable problems have become increasingly prominent, accelerate the transformation of economic development, promote strategic adjustment of economic structure, Become urgent. Therefore, to promote the development of small and micro enterprises to increase small and micro enterprises to adapt to market capacity, to promote the adjustment of industrial structure, more targeted to promote the expansion of domestic demand.

\section{Small and Micro Enterprises and Market Adaptability}

Small micro-enterprise is a small business, family workshop-style enterprises collectively, by Chinese chief economist Professor Lang Xianping. According to the Law of the People's Republic of China on the Promotion of Small and Medium Enterprises and the Opinions of the State Council on Further Promoting the Development of Small and Medium-sized Enterprises, the SMEs are classified into three types: medium, small and micro, according to the enterprise employees, business income, Indicators, combined with industry characteristics. Applicable industries include: agriculture, forestry, animal husbandry, fishery, industry (including mining, manufacturing, electricity, heat, gas and water production and supply industry), construction, wholesale, retail, transportation (excluding (Including telecommunications, Internet and related services), software and information technology services, real estate development and management, property management, leasing and business services, telecommunications, Internet and related services, transportation, real estate, (Including scientific research and technical service industry, water conservancy, environment and public facilities management industry, resident service, repair and other service industry, social work, culture, sports and entertainment industry).

For manufacturing enterprises, small and micro enterprises are generally small in the production scale. Economies of scale in economics described in a certain 
level of science and technology conditions, the enterprise's long-term average cost decreases with the increase in production, while the size of enterprise production to determine the size of the cost of high and small, small-scale production of small enterprises Doomed the cost is relatively high. Small and micro enterprises in the production technology is generally very backward, due to capital constraints, small and micro enterprises in technology and equipment selection can not choose high value, high technology content of equipment, leading to the production of product quality is not as large and medium-sized enterprise quality it is good.

As most small and micro enterprises are usually concentrated in particular market business activities, so usually small and micro enterprises only can provide a single product or service. And most of the small and micro enterprises are fully competitive industry, the ability to resist market changes in the environment is relatively weak. And small businesses mostly for daily necessities of light manufacturing industry, technical content and value-added are low. With the adjustment of the market structure and the change of industrial structure, these small and micro enterprises are facing increasingly severe market competition, the business situation is easily affected by the external market environment. Once the market appears strong competitors and substitutes, Enterprises are likely to face the risk of failure.

\section{Small Micro Enterprise Market Adaptability Factors}

Market financing capacity refers to the ability of enterprises to raise capital by means of money in order to obtain assets. In the modern economy of increasingly credit and securitization, market financing has become the main channel for enterprises to obtain funds, but there are some difficulties for small and micro enterprises. In this paper, small and micro enterprise market financing capacity is mainly from the perspective of the viability of small and micro enterprises, the main factors include business and business credit, effective guarantee value, profitability.

Small and medium-sized enterprises relative to large and medium-sized enterprises in terms of market competitiveness, although weak, which is a direct impact on the life of small and micro enterprises the most critical factor in the length of life. The market competitiveness of small and micro enterprises is related to the survival and development of small and micro enterprises. This article mainly from the development point of view, including: product type, market share, degree of dependence on large enterprises, customer flow stability, employee loyalty.

Market information and quickly reflected to the decision-makers in the hands of effective means to quickly organize the implementation, can greatly improve the small micro-enterprise market response capability, which has a direct impact on the ability of small enterprises to resist market risks, including: market forecasting ability, Ability, risk aversion ability. 
Technology adaptability refers to the ability of enterprises to introduce and research and develop technology in order to adapt to market development and social needs. Enterprises in the market position are determined by the technical status of enterprises. Technology adaptability is to improve the ability of technological innovation and improve the enterprise in the new technology under the impact of rapid adaptability. Mainly include: the proportion of technical personnel, technology import capacity, new product development capabilities.

\section{Enhance Small and Micro Enterprises Market Adaptability Strategy}

Although the market capacity of the chemical enterprise is strong, but the effective guarantee value is not high, taking into account the current financial situation of the enterprise, plant size and production operations, proposed the introduction of new equipment. The introduction of new equipment on the one hand can increase the enterprise fixed assets, in the enterprise needs to market financing, can improve the effective guarantee value; on the other hand, the introduction of new equipment can expand the production scale, if the introduction of different types of new equipment can Increase the enterprise's existing product categories, in short, the introduction of new equipment to improve business efficiency and increase production, so that we can improve the profitability of enterprises, thereby enhancing the market financing capacity of enterprises, and ultimately improve enterprise market adaptability.

At present, XX chemical enterprise market competitiveness is strong, more types of products, enterprises in the region where the market share is also larger, has a certain influence, and customer flow is relatively stable in recent years and old customers to maintain a more stable cooperation relationship. But in the enterprise is currently attached to a higher degree of large enterprises, so that both conducive to the development of enterprises side, but also have a negative side. Advantageously, a stable relationship with large firms can increase revenues and provide opportunities for growth. Unfortunately, if you lose the support and cooperation of large enterprises, you are exposed to a high degree of risk . Therefore, XX enterprises should understand the market demand in the case of solid cooperation with the old customers, to ensure that the profits of enterprises under the premise of the development of new customers, both to improve sales.

Evaluation results show that the enterprise's ability to respond to strong, sectoral system flexibility, information transmission speed in general, strategic adjustment capacity in general. To improve the speed of information transmission, the company currently has no introduction of management information technology, a small number of employees, there is no need to introduce information management network to increase business management costs, so XX enterprises present situation, proposed the establishment of a hierarchical relationship network. On the one hand to promote the transfer of information and staff exchanges, on the other hand easy to manage, to promote sector flexibility 
management. Each enterprise is in accordance with the plan production and management, and this intermediate communication channel is indispensable. Facilitating communication between employees who are not often interacting with each other can enable unplanned programs to self-organize and move forward, enabling enterprises to adapt to changes in the market and improve their market adaptability.

Through the comprehensive evaluation of the market adaptability of small and micro enterprises, the chemical industry's technology adaptability is weak and the new product development ability is not. On the current situation of the enterprise, proposed the introduction of technical personnel. The proportion of the current technical staff of the enterprise is $1 / 4$, in the industry at a low level, but enterprises can not quickly change the current status of technology adaptability, the need for the gradual introduction of technical personnel. Technical personnel for the enterprise's technology development plays a crucial role in technology talent can improve enterprise $\mathrm{R} \& \mathrm{D}$ capabilities, but also to improve the understanding of enterprise employees for technology, improve the overall innovation and development capabilities. Improve the proportion of technical personnel, can drive the development of enterprise technology research and development, and gradually improve the technology adaptability of enterprises, thereby improving market adaptability.

\section{Conclusion}

Based on the study of domestic and foreign relevant theories and achievements on market adaptability of small and micro enterprises, this paper constructs the index system of market adaptability evaluation of small and micro enterprises, and through the evaluation results of market adaptability of small and micro enterprises, The Countermeasures to Improve the Adaptability of Small - and micro - enterprises.

\section{Acknowledgement}

The major problems in the management of higher education in Shaanxi: A study on the innovation and entrepreneurship education of college students in Shaanxi

\section{References}

[1] Lu Xiaoping. Micro-enterprise growth in the obstacles and countermeasures [J]. Shanghai Enterprises. 2014 (02)

[2] Zhang Zhen, Zhu Bin. Research on the Financing Dilemma of Small and Micro Enterprises Based on Information Asymmetry Perspective [J]. SME Management \& Technology (Middle Ages). 2014

[J]. Management and Technology of Middle and Small Enterprises. (In Chinese).

(3) Zhou Aifang, Li Li. On small and micro enterprises financing difficult 
problems and countermeasures [J] .Journal of Economics of Science and Technology, 2011 (4)

[5] Wang Yifeng, Wu Yaping. Development of small and micro enterprises based on life cycle theory [J] .Technology Progress and Policy, 2013 (1) 